\title{
LA PLATERÍA MEXICANA A TRAVÉS DE LA DOCUMENTACIÓN DEL ARCHIVO DE LA ARQUIDIÓCESIS: MEMORIAS DE ADEREZOS DE PLATA DE MEDIADOS DEL SIGLO XVII
}

\author{
THE MEXICAN SILVER-SMITHING THROUGH THE \\ DOCUMENTS OF THE ARCHDIOCESE FILES: REPORTS \\ OF SILVER REPAIRS IN THE MIDDLE OF \\ THE $17^{\text {th }}$ CENTURY
}

Manuel Varas Rivero

Universidad de Sevilla. España

mvr@us.es

\begin{abstract}
Se dan a conocer y se analizan en este trabajo varios documentos inventariales inéditos sobre aderezos y arreglos de la platería de la catedral de México a mediados del siglo XVII.

Palabras clave: platería; catedral; México; siglo XVII; aderezo.

A number of unpublished inventorial documents about silver-smithing repairs and decorations of the Cathedral of Mexico in the middle of the 17th century are unveiled and analyzed in this paper.

Keywords: silver-smithing; cathedral; Mexico; $17^{\text {th }}$ century; repair.
\end{abstract}

Desaparecida la mayor parte del tesoro suntuario de la catedral de México, la documentación de la Arquidiócesis es fundamental como instrumento para el estudio del mismo. En este trabajo damos a conocer y analizamos unos documentos inéditos que reflejan una gran actividad en torno a la ejecución y arreglo de piezas de plata, en una época, años centrales del siglo XVII, en la que el tesoro catedralicio adquiere una gran riqueza.

Son memorias de aderezos y arreglos de plata de existencia previa, por lo que su contenido se ciñe a las operaciones técnicas de tales aderezos y a la simple 
mención de las piezas. Se añade a veces alguna información sobre el aspecto de los objetos y datos económicos de gastos, cobros y recepción de dinero en relación a tales operaciones ${ }^{1}$.

El primero de los cinco documentos analizados registra los aderezos realizados en la plata catedralicia de México en 1658 y el costo de aquellos ${ }^{2}$. Los aderezos son de importancia menor, ya que en la mayoría de los casos se hicieron soldaduras de pies, arandelas, superficies quebradas, eslabones o figuras sueltas, además de algunos remiendos y el desabollado de alguna pieza. El costo también fue menor: 32 pesos.

El aspecto más destacado es la presencia de la firma del platero que realiza los arreglos en la plata catedralicia ese año, el maestro de platero Nicolás Ruiz. Hemos podido identificarlo con el maestro platero Nicolás Ruiz que aparece documentado en Puebla los años 1680-16963. Es poco lo que conocemos de él. Por ahora lo único que podemos asegurar es que en 1658, como documentamos aquí, aparece ya como maestro platero trabajando en la capital virreinal en labores menores del tesoro catedralicio y, por tanto, al servicio del cabildo eclesiástico, probablemente en una época de inicio de su carrera como artista, ya que, por otro lado, Pérez Morera lo documenta en Puebla veinte años después, una prueba más del trasiego de plateros entre ambas localidades a lo largo del período virreinal ${ }^{4}$. Tal vez podría deducirse por la cronología que el maestro, tras unos inicios modestos en México, alcanza la estabilidad como artífice en Puebla. Más adelante completamos los datos conocidos de este platero.

Volviendo a la memoria y su carácter, debe anotarse que este tipo de testimonios, a diferencia de los inventarios periódicos, apenas ofrece datos sobre las piezas concretas, por lo que resulta imposible identificar los objetos nombrados y su estilo o época de ejecución. Solo podemos constatar qué tipologías aparecen y esbozar alguna débil hipótesis sobre algunas de las piezas partiendo del contenido de los inventarios catedralicios publicados.

Las tipologías más frecuentes en estas relaciones de aderezos son aquellas que más uso tienen -pontificales, procesionales y de capilla-. La causa del deterioro

${ }^{1}$ Quiero expresar mi mayor agradecimiento al profesor, amigo y compañero en las labores académicas D. Jesús Aguilar por proporcionarme los documentos publicados en este trabajo.

2 Archivo Histórico de la Arquidiócesis de México (A.H.A.M.), Documentos novohispanos, Fondo episcopal, caja 007, expediente 006, f. de encabezamiento-1r. Por razones de espacio no añadimos un apéndice con los documentos analizados.

3 PÉREZ MORERA, Jesús: "El Gremio de plateros poblano. Nómina cronológica de artífices (1580-1820)", en El sueño de El Dorado. Estudios sobre la plata iberoamericana ( siglos XVI-XIX). León, 2012, pp. 235-263.

${ }^{4}$ Ibidem, pp. 239, 240 y 252. En la lista publicada por Pérez Morera aparece también un Nicolás Ruiz “el Mozo”, activo en Puebla como oficial en 1703, que quizás guarde una relación familiar con el platero documentado aquí. Véase p. 254 del estudio citado. 
también puede deberse al paso del tiempo, puesto que no sabemos en la mayoría de los casos a qué período pertenecen los objetos que se arreglan, dándose la posibilidad de que en algún ejemplo estemos ante piezas antiguas de la centuria anterior. No obstante, y suponiendo que las piezas quizás son menores y que se funden con cierta periodicidad por los cambios de gusto, entendemos que en su mayoría pudieron pertenecer a etapas anteriores no muy lejanas. Más adelante propondremos una hipótesis para contextualizar el contenido de éste y del resto de documentos.

El número de tipologías es amplio: ciriales -uno "blanco", es decir, de plata en su color-, incensarios, blandones diversos, dos lámparas, una fuente y un aguamanil dorados, un cetro, un atril, una cruz de manga y unas "palabras", suponemos que de la consagración, a la que se soldó una figura -tal vez tenía forma de custodia- $-^{5}$. Para esas fechas el tesoro de la catedral mexicana ya acumulaba una enorme y rica colección de objetos suntuarios, especialmente desde los tiempos del arzobispo don Pedro de Moya de Contreras, cuando se elabora el importante inventario de 1588. Aún en la primera mitad del siglo XVII se acrecienta ese tesoro, si bien se sabe que se funden piezas antiguas para elaborar nuevas preseas en el nuevo estilo manierista y se inicia un interés cada vez mayor por el adorno de piedras preciosas, como demuestra el temprano ejemplo de la rica custodia de don Juan de Salcedo, donada en $1626^{6}$.

A resultas de todo ello solo podemos anotar algún comentario de unas piezas inidentificables en su mayoría. El cetro aderezado bien pudo ser uno de los dos conservados en 1632, cincelados y fundidos, probablemente de estilo bajorrenacentista ${ }^{7}$. Hasta cuatro nuevos aguamaniles de plata dorada y estilo bajorrenacentista con mascarones, figuras y temas vegetales se registran en 1632. Sin

5 A.H.A.M., Documentos novohispanos, Fondo episcopal, caja 007, expediente 006, f. 1r. Por algunas descripciones de los inventarios, entendemos que las lámparas que aparecen en estos documentos son de "plato" o vaso, siguiendo los modelos españoles renacentistas y manieristas.

${ }^{6}$ Los inventarios catedralicios aparecen reseñados con mucho detalle en TOUSSAINT, Manuel: La Catedral de México y el Sagrario Metropolitano. Su historia, su tesoro, su arte. México, 1973, pp. 171-213. Sobre el interés por las piedras preciosas véanse ROMERO DE TERREROS, Manuel: Las artes industriales en la Nueva España. MéxicoBarcelona, 1923, pp. 33 y ss.; y VARAS RIVERO, Manuel: "El documento inédito de la donación a la catedral de México del famoso y desaparecido relicario de don Juan de Salcedo", Laboratorio de Arte, 26, 2014, pp. 121-136.

7 TOUSSAINT, M.: La Catedral de México..., op. cit., p. 188. Interpretamos del análisis de Toussaint que otros cetros platerescos preexistentes fueron fundidos en el XVII. Siguiendo modelos españoles bajorrenacentistas, los cetros y ciriales tendrían quizás macollas globulares y gallonadas o formadas por elementos geométricos y tornapuntas o cilíndricas. Por supuesto, macolla y pértiga irían cinceladas con relieves cada vez más planos de temas vegetales, mascarones, "ces", costillas y botones. 
contar con otros ejemplares anteriores, tal vez el citado en el documento es uno de esos cuatro ${ }^{8}$. La cruz mencionada tal vez sea la cruz grande de plata dorada con manzana cincelada, con la figura de un pelícano y 22 marcos de peso, que según los inventarios de 1632 y 1654, se usaba para las procesiones ${ }^{9}$. El resto de objetos -lámparas, blandones, fuentes, incensarios, etc.- aparece en número tan grande en los inventarios que es imposible hacer cualquier apreciación, salvo suponer que en la mayoría de los casos serían ejemplares de estilo bajorrenacentista y manierista -decoraciones vegetales o de cintas planas cinceladas o repujadas y estructuras rígidas aún-, pues el desgaste a mediados del siglo XVII implica un uso y un deterioro a lo largo de las décadas previas, que coincide con el desarrollo de esos estilos ${ }^{10}$.

En 1659 se hacen grandes gastos en la compra o arreglo de bienes muebles y ornamentos para la iglesia y sacristía de la catedral por orden de Bartolomé de Quevedo, sacristán mayor desde $1654^{11}$. Esta segunda memoria es más amplia que la anterior y más variada en los enseres reseñados ${ }^{12}$.

En primer lugar llama la atención el importante gasto en compra y aderezos de prendas y ornamentos litúrgicos, a los cuales se dedica bastante más de la mitad del montante total, 635 pesos. Solo en la confección de 15 albas de ruán se gastaron 404 pesos. A ello se añaden otros gastos en frontales y manteles para

${ }^{8}$ No sabemos si estos aguamaniles respondían al modelo italiano de cuerpo globular -menos frecuente- o al tipo de jarro de pico, del que hablamos más adelante -más habitual en España y América-.

${ }^{9}$ Ibidem, pp. 188 y 193. No sabemos si los dos inventarios hacen alusión a una sola cruz o son dos distintas. En este último caso, es posible que la nueva cruz incorporase formas manieristas.

${ }^{10}$ Desde fines del siglo XVI se desarrolla bajo modelos españoles en la Nueva España el Bajorrenacimiento, que simplifica la decoración renacentista con motivos geométricos planos de "ces" sobre fondos con picado de lustre, botones y costillas. Desde 1600 el Manierismo, llegado de España, incorpora sobre la base bajorrenacentista, que se mantiene, el gusto por el dorado de la plata, el uso del esmalte en los botones o espejos y mayor simplicidad con estructuras rígidas y zonas de plata lisa. Precisamente en los años de datación de los documentos de este trabajo se empieza a introducir, también desde España aún, el gusto por unas formas más movidas y suaves y una decoración naturalista vegetal relevada

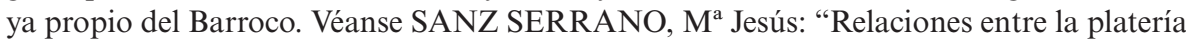
española y la americana durante el siglo XVII", en III Jornadas de Andalucía y América. Vol. II. Sevilla, 1984, pp. 17-29; ESTERAS, Cristina: "Platería Virreinal Novohispana. Siglos XVI-XIX”, en El Arte de la Platería Mexicana. 500 años. México, 1989, pp. 79-119; y ESTERAS, Cristina: "Aproximaciones a la Platería Virreinal Hispanoamericana”, en Pintura, Escultura y Artes Útiles en Iberoamérica. 1500-1825. Madrid, 1995, pp. 377-403.

${ }_{11}$ TOUSSAINT, M.: La Catedral de México..., op. cit., pp. 172 y 195. Recién nombrado sacristán mayor, realiza el inventario de 1654 del tesoro catedralicio.

12 A.H.A.M., Documentos novohispanos, Fondo episcopal, caja 007, expediente 006, f. de encabezamiento y ff. $3 \mathrm{r}-4 \mathrm{v}$. 
altar, flecos de seda y oro, puntas, hilos, paños de lana, fundas para mangas de cruces, purificadores y corporales, que renovaron parte del ajuar litúrgico más básico. El resto de bienes es variopinto. Destacan 4 misales plantinos -100 pesos-, los enseres y arreglos de la capilla de San Felipe, realizados justo 30 años después de la primera procesión convocada en México en honor del santo ${ }^{13}$, y un "candelón" de bronce para el coro "con sus arbotantes" y "arandelas". Nos parecen interesantes dos entradas singulares ${ }^{14}$. La primera refiere los aderezos, algunos de mantenimiento -nuevos brazos de carga por estar rotos y añadir goznes-, otros estéticos - plateado- de "las andas de madera que sirven a la custodia de plata". Sobre estas antiguas andas es poco lo que sabemos. Deben ser las que empiezan a realizarse en 1602, cuando se adereza el altar mayor catedralicio ${ }^{15}$. Suponemos que es la misma pieza mencionada en el inventario de 1654. Se dice en él que es obra del arzobispo Guerra (1608-1612) y que fue renovada por el arzobispo Mañozca (1643-1650). Por la escueta descripción se deduce que era un tabernáculo con planta centralizada de cruz griega que se usaba en el altar mayor para cobijar la antigua custodia de torre del siglo XVI. Posiblemente desapareció en el siglo XVIII cuando fue incorporado el famoso "Ciprés" al altar mayor ${ }^{16}$. Por las fechas citadas, tendría el aspecto de un templete clásico con elementos manieristas y su renovación tal vez incluyó nuevos adornos geométricos y esmaltes de tipo purista. La cruz griega adquiere enorme desarrollo en España en esos años en andas, custodias y construcciones efímeras, por lo que parece debió seguir esos modelos ${ }^{17}$.

${ }^{13}$ Se produjo en febrero de 1629. Dedicada al protomártir mexicano San Felipe de Jesús desde 1636, pocos años después de su beatificación, la capilla fue renovada en sus ornamentos totalmente en el siglo XVIII. Véanse MARROQUI, J. M.: La ciudad de México. T. 3. México, 1903, p. 425; y TOUSSAINT, M.: La Catedral de México..., op. cit., p. 163.

14 A.H.A.M., Documentos novohispanos, Fondo episcopal, caja 007, expediente 006, f. $3 r-3 v$.

15 TOUSSAINT, Manuel: Paseos coloniales. México, 1939, pp. 2 y 3. Entre los aderezos del altar mayor de 1602 se menciona "aparejar y plata y hechura de las andas de la custodia".

${ }^{16}$ Debió sustituir a otras andas renacentistas de madera citadas en el inventario de 1588. TOUSSAINT, M.: La Catedral de México..., op. cit., pp. 185 y 195. El "ciprés" fue ejecutado en 1741, véase ESTERAS, C.: "Platería Virreinal Novohispana...", op. cit., pp. 105 y ss.

17 Véase VARAS RIVERO, Manuel: "Sobre la orfebrería y la arquitectura efímera. Apuntes sobre su conexión formal a través de algunos ejemplos sevillanos del siglo XVI y primer tercio del XVII", Laboratorio de Arte, 19, 2006, pp. 101-121. Debió parecerse a las custodias españolas manieristas de la primera mitad del seiscientos, todas de planta cruciforme y con columnas agrupadas en los vértices, como las custodias de la Hermandad Sacramental del Salvador de Sevilla, coetánea de las andas mexicanas aderezadas, o de Santaella, Córdoba (1656). Pueden verse en VV. AA.: El Fulgor de la Plata. Sevilla, 2007, pp. 272-275. 
También sobresale el aderezo de la llamada "cruz chica de manga", a la que se añade un "obalo". No sabemos qué cruz de las numerosas mencionadas en los inventarios podría ser, tal vez sea una nueva, de plata dorada sobre madera, que aparece en el inventario de 1649, de la que se dice estar esmaltada en azul. El uso de óvalos, esmaltados o no, es propio del Bajorrenacimiento y el Manierismo. Pensamos mejor que fue una pieza reciente la aderezada - ¿la cruz del 49?-, y no la renovación de una cruz anterior, para la cual la incorporación de un solo óvalo sería insuficiente para un cambio de estilo.

Finalmente se consignan las entradas del dinero necesario para realizar dichos aderezos, constatándose el predominio de las donaciones ${ }^{18}$. La venta de una reja de hierro y las donaciones de los señores hacedores y diversos patronos -doctores Arce y Aguirre, el licenciado Encinas y el patrón de la capilla de San Felipe, muy beneficiada, don Luis de Porras- permitieron reunir gran parte del monto final.

El tercer documento es una nueva memoria de los gastos y aderezos realizados en la plata catedralicia durante el año de $1660^{19}$. Apenas hay cambios respecto a los documentos anteriores. Aparece una gran cantidad y variedad de piezas de frecuente uso litúrgico, a las que se realizan pequeñas operaciones: soldar piezas quebradas, chapas, argollas, eslabones y asillas -incluida la soldadura de un atril a su facistol-; desabollar, añadir "dientes" de plata, hembrillas, tornillos y "birolas" - tapa en el extremo del cañón de un cetro- y enderezar cartelas. La importante actividad de ese año aumentó los gastos hasta los 37 pesos. Las tipologías se repiten: blandones de diverso tamaño, un facistol, un cetro, lámparas, una fuente dorada, una naveta, incensarios, unas palabras, un cirial, hisopos y jarras. La ausencia de descripción hace imposible identificar las piezas o hacer consideraciones concretas sobre ellas, salvo constatar la amplitud alcanzada por el tesoro en este momento, aspecto que los inventarios prueban claramente. En su mayoría serían piezas bajorrenacentistas o puristas de las décadas anteriores.

Un cuarto documento es otra memoria de aderezos catedralicios realizada en 1666 y firmada al año siguiente ${ }^{20}$. El dato más importante en este caso es la firma de verificación del maestro platero que realizó los arreglos, cuyo nombre ha resultado ser inédito. En efecto, el maestro de platero Melchor de Salazar y Leiba,

18 A.H.A.M., Documentos novohispanos, Fondo episcopal, caja 007, expediente 006, f. 4r-4v. Destacan algunas donaciones para la capilla de San Felipe de la catedral mexicana, de la que se dice se vendieron sus rejas por algo más de 400 pesos. Entre los donantes se menciona expresamente a los doctores Arce y Aguirre, al licenciado Encinas y a don Juan de Porras.

19 A.H.A.M., Documentos novohispanos, Fondo episcopal, caja 008, expediente 006, f. de encabezamiento y ff. 1r-2r.

${ }^{20}$ A.H.A.M., Documentos novohispanos, Fondo episcopal, caja 009, expediente 036, f. de encabezamiento y ff. 1r-1v. 
no aparece en las relaciones consultadas ${ }^{21}$. En esta ocasión la lista de registros es más corta, pero se añade alguna tipología ausente en las memorias anteriores. Es el caso de tres vinajeras, dos doradas y una plateada o "blanca", con pequeños arreglos de soldadura. De las doradas se aclara que tienen "un pie y tapaderas araneadas"22. Como pieza esencial de la liturgia, es tan alto su número en los inventarios que resulta imposible identificarlas. En los inventarios de mediados de siglo las vinajeras doradas son abundantes, signo claro del gusto manierista por ese acabado de la plata. También aparece un portapaz como novedad que tampoco podemos identificar ${ }^{23}$. El resto de piezas son las habituales: blandones "grandes" -tal vez los blandones "ricos" que se hicieron a principios del siglo XVII, citados en el inventario de $1632-{ }^{24}$, una fuente dorada, incensarios, una naveta, un facistol - del que carecemos de noticias ${ }^{25}$, una cruz de manga -tal vez la procesional antes mencionada- $\mathrm{y}$ un acetre. Los aderezos son simples -pequeñas soldaduras, atornillados y aplicación de hembrillas- y el gasto pequeño, 13 pesos.

El último documento, el quinto, consigna los aderezos realizados en la plata de la catedral de México en $1667^{26}$. Esos arreglos fueron realizados por el platero Melchor de Salazar y Leiba, que firma el documento. No ofrece novedades respecto a las tipologías que incluye. Un blandón grande y otro pequeño, vinajeras -deshechas según el documento-, tres incensarios, el facistol, ciriales, un cetro, una naveta y un hisopo, reciben pequeños arreglos de soldadura, atornillados y añadidos pequeños de plata, cuyo importe es también pequeño, 21 pesos.

${ }^{21}$ Remitimos a la bibliografía señalada en la nota 3. La memoria aparece firmada por don Andrés de Figueroa.

22 No sabemos exactamente el significado del término "araneado". Como tal adjetivo, no aparece en el Diccionario de Autoridades de la Real Academia Española de la Lengua (1726-1739) ni en el Tesoro de la Lengua Castellana o Española de Covarrubias (1611). El primero incorpora el término "arana", que significa hacer trampa o fraude. Por una parte podría entenderse que son falsas, aunque también podría aludir a la morfología de la tapadera en forma de rana -con estructura ondulada, como a veces son las tapaderas de vinajeras en la época-.

${ }^{23}$ Sería de tipo arquitectónico, lo habitual entonces, con composición albertiana de soportes, arco central y remate. Tal vez con hermes como elemento sustentante si es de fines del XVI.

${ }^{24}$ TOUSSAINT, M.: La Catedral de México..., op. cit., p. 187.

${ }^{25}$ Solo hemos visto en los inventarios diversos atriles de plata, algunos "ricos" y grandes, a fines del siglo XVI y principios del XVII. Ibidem, pp. 185 y 187.

${ }^{26}$ A.H.A.M., Documentos novohispanos, Fondo episcopal, caja 009, expediente 015, f. $1 \mathrm{r}-1 \mathrm{v}$. 
La gran mayoría, por no decir la totalidad, de estas piezas se perdieron con el tiempo, presas de fundiciones debidas a cambios de gusto y, sobre todo, para los tesoros catedralicios de México, por los acontecimientos políticos del siglo XIX ${ }^{27}$.

En general estos documentos testimonian una labor prosaica y cotidiana, poco creativa pero interesante por los datos concretos, ya comentados, que se incluyen en ellos.

Resumiendo esa información e intentando en lo posible contextualizar el contenido de las memorias y su significado, apreciamos que a mediados del siglo XVII el tesoro catedralicio mexicano se mantiene vivo con gran cantidad de piezas en uso que generan trabajos de aderezo constantes. Son labores muy variadas pero de escasa entidad. Sin mencionar en ningún caso la fundición de obras aunque estos procesos son conocidos por otro tipo de documentos-, aparecen las siguientes: predominan las soldaduras de piezas sueltas -arandelas, cartelas, peanas, chapas, tapaderas, asillas e incluso figuras, en unas palabras- o de elementos quebrados o abiertos en una pieza -suelos de bandejas, linternillas de lámparas-, hechuras de pequeños elementos y añadidos de eslabones, hembrillas, "birolas" o dientes de plata.

En general pensamos que los documentos registran labores rutinarias de limpieza -actividad explícitamente mencionada en alguno de ellos- y arreglo, pues además de su escasa entidad, se realizan de forma periódica en los meses de febrero y marzo, época de Cuaresma y de intensa actividad litúrgica en el calendario eclesiástico. No obstante, concurren en esos años circunstancias particulares que debieron influir en la proliferación de aderezos, como veremos a continuación.

Los gastos de orfebrería son mínimos, 103 pesos en diez años -más allá de que otras memorias no localizadas reflejen trabajos en otros años dentro del período-, pero manifiestan una labor constante de mantenimiento en una época concreta de grandes fiestas y celebraciones. En efecto resulta llamativa la coincidencia cronológica evidente entre esta continuada documentación del aderezo de piezas en uso en la catedral mexicana y el desarrollo de grandes y significativos eventos litúrgicos - procesiones, misas y funciones varias- que exigieron un empleo intensivo de todo tipo de elementos suntuarios, tanto procesionales como pontificales y de capilla.

Los documentos que corresponden a los años 1658-1660, deben vincularse a los trabajos finales de edificación interior del templo catedralicio y, consecuentemente, a los fastos realizados en la primera Dedicación de la Catedral de México, celebrada los días 1 y 2 de febrero de 1656. A la gran procesión del día 1, en la que participaron cofradías, hermandades, corporaciones religiosas y civiles, el cabildo catedralicio y el propio virrey, se unieron las grandes funciones del día 2, con misas y procesión interior, y nueve días más de fiesta, con la celebración incluida de

${ }^{27}$ Véanse DE VALLE-ARIZPE, Artemio: Notas de Platería. México, 1941; y TOUSSAINT, M.: La Catedral de México..., op. cit., pp. 217-218. 
la fiesta de San Felipe de Jesús ${ }^{28}$. Estos eventos, sin duda, provocaron un deterioro importante de los enseres, al que se sumó el uso litúrgico cotidiano posterior y las continuas obras de terminación del templo. A propósito de esto último, a las fiestas hay que sumar el continuado estado de obras de la catedral, que tuvo que ser limpiada de escombros y polvo durante tres días por 200 hombres para la celebración de la Dedicación, circunstancia que sin duda tuvo que afectar a la conservación, traslado y uso de las piezas ${ }^{29}$. A los mismos motivos debe corresponder el gran gasto en ornamentos realizado en 1658, ya comentado anteriormente.

Los documentos que aluden a los aderezos de 1666-1667, al margen de la rutina anual, aparecen contextualizados en los grandes eventos celebrados esos dos años en un templo ya terminado en su espacio interior. La primera gran ceremonia en el interior concluido fueron las honras fúnebres de Felipe IV, la noticia de cuya muerte llegó a Nueva España en mayo de 1666. Fueron celebradas en el verano de ese mismo año. De sobras es conocido el uso intensivo de luminarias y enseres de plata en altares y túmulos funerarios en estos casos, por lo que no extraña el buen número de desperfectos que aparecen aderezados en las memorias de esos dos años ${ }^{30}$. A esos eventos hay que añadir la segunda y definitiva Dedicación del templo metropolitano, llevada a cabo con grandes procesiones y oficios los días 21 y 22 de diciembre de 1667. Como atestiguan las crónicas, fue realizada con grandes fastos y un uso importante del tesoro ${ }^{31}$.

Debe destacarse igualmente la documentación en las memorias de dos plateros, uno de ellos inédito. Se trata de Nicolás Ruiz, que trabaja para la catedral en 1658 y al que vemos unos años después asentado en Puebla ${ }^{32}$, y de Melchor de Salazar y Leiba, inédito, que trabaja en la catedral mexicana en 1667 y 1668 . A propósito del primero, Nicolás Ruiz, es significativo su traslado a Puebla, al menos veinte años después de aparecer documentado en la catedral metropolitana. Sabemos que, al menos hasta 1660 la platería de Puebla es obra de orfebres con tienda abierta en México, dadas las prohibiciones al respecto impuestas por el virreinato, que el trasiego entre Puebla y México de oficiales es una constante y que a fines del seiscientos, relajadas las normas, comienza el gran desarrollo de la platería poblana de manos de orfebres locales y a través del establecimiento de un

${ }^{28}$ Los trabajos constructivos del interior catedralicio no acabaron del todo hasta 1667. Sobre esos trabajos y sobre las fiestas celebradas en 1656, pueden verse TOUSSAINT, M.: La Catedral de México..., op. cit., pp. 33-35 y 43-45; y MARROQUI, J. M.: La ciudad de México. T. 3, op. cit., pp. 11, 12 y 248.

29 TOUSSAINT, M.: La Catedral de México..., op. cit., p. 43.

${ }^{30}$ Ibidem, pp. 53-55.

${ }^{31}$ Ibid., pp. 47-50.

32 Véase nota 4. 
gran número de maestros foráneos. ${ }^{33}$ En ese contexto se sitúa Nicolás Ruiz. En 1658 lo documentamos nosotros trabajando modestamente para la catedral de México a una edad juvenil -dadas las fechas de estancia en Puebla-. No sabemos si es poblano establecido en la capital o nativo. Pérez Morera lo documenta junto a su hijo, José Ruiz, en Puebla entre 1680 y 1696, realizando una lámpara, un recado de vinajeras y un par de atriles para la parroquia de San José34. Aunque no lo explicita lo supone poblano, por lo que su estancia en la capital como aderezador del tesoro hay que entenderla como una primera etapa profesional, alejada de una Puebla difícil para el ejercicio de la platería en ese momento. Es posible que para 1666, momento en el que esas tareas documentadas las realiza otro platero, Nicolás Ruiz ya se hubiese trasladado a Puebla. Melchor de Salazar y Leiba es un orfebre inédito, pues no aparece en ninguno de los estudios consultados. Ambos aparecen realizando labores modestas para la catedral metropolitana. No sabemos si sus contratos incluían labores de elaboración y hechura de piezas nuevas. No obstante, la contratación por los cabildos de plateros para realizar exclusivamente actividades de limpieza y aderezo fue una constante en Nueva España en ese momento ${ }^{35}$.

En cuanto a las tipologías suntuarias aderezadas, la mayoría son piezas de uso litúrgico cotidiano que quizás podrían no ser muy antiguas, tal y como argumentamos más arriba. Pensamos así que su estilo formal, siguiendo cánones castellanos, salvo quizás algún motivo decorativo autóctono, debía andar entre lo bajorrenacentista, en las más antiguas, y lo manierista o purista. Con tan escasos datos, solo podemos hacernos una débil idea de su aspecto considerando algunos ejemplares conservados coetáneos, es decir, del período anterior a la data de los documentos, bien mexicanos o bien españoles, que les sirvieron de modelo.

Las cruces aderezadas debían ser muy parecidas al ejemplar mexicano del Museo Nacional del Virreinato, INAH (Tepotzotlán), datado hacia 1630. De estética bajorrenacentista presenta estructura moderna de brazos rectos con óvalos extremos y decoración de "ces" planas y espejos sobre picado de lustre. Del mismo modo, los candeleros mexicanos del Museo Franz Mayer, fechados hacia 1640, ofrecen una estructura superpuesta y rígida de tipo bajorrenacentista, aunque el nudo aovado es ya puramente manierista, y una decoración prebarroca

33 PÉREZ MORERA, J.: "El gremio de plateros poblanos...", op. cit., pp. 235-263; PÉREZ MORERA, Jesús: "Formas y expresiones de la platería barroca poblana. Repertorio decorativo, técnicas y tipologías", Anales del Instituto de Investigaciones Estéticas, 100, 2012, pp. 119-170.

34 PÉREZ MORERA, J.: "El gremio de plateros poblanos...", op. cit., pp. 237 y 252.

${ }^{35}$ GARDUÑO PÉREZ, L.: Un siglo de platería en la Catedral de Puebla a través de sus inventarios de alhajas (siglo XVIII). Tesis doctoral Universidad Nacional Autónoma de México, 2011, pp. 55-58. 132.248.9.195/ptd2012/marzo/0678194/0678194_A1.pdf (Consultado 7-11-2016). 
-naturalista- que bien podrían darnos una idea del aspecto que tuvieron los numerosos blandones aderezados. En más de un caso pudieron ser blandones más modestos de estructura simple y plata lisa ${ }^{36}$. La lámpara mexicana de la catedral de Jaca (Huesca, España), fechada en 1611, con estructura rígida y geométrica de formas convexas superpuestas y decoración plana de "ces", nos permite imaginar las lámparas citadas en las memorias. Las vinajeras mexicanas de 1661 de la mencionada catedral de Jaca, manieristas, sobredoradas, de cuerpo troncocónico y con decoración plana y óvalos de esmaltes, pueden remitirnos a las documentadas. Para los acetres, lo plateros mexicanos, partiendo de los modelos castellanos, comienzan a tipificar un modelo concreto en esta época formado por una superposición de cilindros y elementos convexos sobre pie circular. El ejemplar mexicano de Castro Urdiales (Cantabria), fechado en 1659, pertenece a ese modelo y muestra cómo se mantiene aún la típica decoración plana de "ces", cartelas y espejos ovales, aunque tal vez las piezas arregladas encajaran mejor en el modelo cilíndrico de cubo que es propio del siglo $\mathrm{XVI}^{37}$.

Las fuentes doradas aderezadas pudieron ser de condición modesta, sin adorno $^{38}$. Pero también pudieron ser ricas. Las mexicanas sobredoradas de la iglesia de Santa Cruz de Écija (Sevilla) y de la catedral de Sevilla, fechadas en el segundo cuarto del siglo XVII, muestran claramente el compromiso estilístico entre lo bajorrenacentista y lo manierista que pudieron ostentar las arregladas en México. La primera muestra decoración plana vegetal y gran número de espejos y gallones esmaltados, concentrándolos en la zona intermedia siguiendo pautas novohispanas. La segunda cincelada y repujada con "ces" planas, gallones y espejos, resulta de tono bajorrenacentista, pero el tratamiento más volumétrico de los relieves y el uso de motivos nuevos como las veneras la acercan ya a postulados barrocos $^{39}$.

Las navetas e incensarios seguirían modelos españoles convencionales, con decoraciones planas de "ces" y vegetales ${ }^{40}$. Las jarras mencionadas en las memorias

${ }^{36}$ De ese tipo, con peana circular simple y astil abalaustrado sin labrar, son los cordobeses, ejecutados hacia 1615-30, del convento de San José de Antequera (Málaga). VV. AA.: El Fulgor de la Plata..., op. cit., p. 238.

${ }^{37}$ Todos los ejemplos mencionados pueden verse en ESTERAS, C.: "Catálogo", en El arte de la Platería mexicana. 500 años..., op. cit., n 28, 32 y 39; y en ESTERAS, C.: "Platería Virreinal Novohispana”, en El arte de la Platería..., op. cit., p. 94.

${ }^{38}$ Como la madrileña del Museo Lázaro Galdiano de Madrid, de 1647-1652. Víctima de fundiciones este tipo de fuentes, pese a ser abundantes en la época, hoy apenas se conservan. CRUZ VALDOVINOS, José Manuel: Platería en la fundación Lázaro Galdiano. Madrid, 2000, pp. 182-183.

39 Pueden verse en SANZ SERRANO, M ${ }^{\mathrm{a}}$ Jesús: La Orfebrería Hispanoamericana en Andalucía Occidental. Sevilla, 1995, pp. 28-31, nº 3 y 4.

${ }^{40}$ Así se ve en los ejemplos mexicanos de colección particular y fechados en la primera mitad del siglo XVII que aparecen en ANDERSON, Lawrence: El arte de la Platería 
pensamos que pudieron corresponder al tipo más común de la época: el jarro de pico. Aunque de uso civil en origen, se incorporaron en España y América a los rituales litúrgicos. No sabemos si las aderezadas fueron ricas o modestas. La jarra mexicana datada en 1625-30 del Museo Lázaro Galdiano de Madrid, es ejemplo representativo de la impronta castellana que impera en lo formal en estos años: a su cuerpo cilíndrico con base semiesférica se adosan asa geométrica en forma de 5 o 7, pico vertedor con mascarón, friso horizontal separador de campos y acostillamientos. El gusto por el burilado plano y algunas zonas lisas completan su configuración manierista. A este tipo o al modesto de plata sin labrar debieron pertenecer nuestras piezas ${ }^{41}$.

Fecha de recepción: 28 de enero de 2017

Fecha de aceptación: 9 de febrero de 2017

en México. 1519-1936. T. II. Nueva York, 1941, nº de catálogo 64 y 82.

${ }^{41}$ Puede verse en CRUZ VALDOVINOS, J. M.: Platería en la Fundación..., op. cit., pp. 189-191, no 78; y ESTERAS, Cristina: Marcas de Platería hispanoamericana: siglos XVI-XX. Madrid, 1992, p. XXII. 